\title{
Analisis Buku Dongeng Si Kancil Karya Tira Ikranegara dalam Peningkatan Nilai Moral
}

\author{
Imam Setyo Wibowo ${ }^{1 *}$, Muhammad Arief Budiman², Mei Fita Asri Untari ${ }^{3}$ \\ 1,2,3 Universitas PGRI Semarang, Semarang
}

A R T I C L E I N F O

Article history:

Received 15 May 2018

Received in revised form 10 Juny 2018

Accepted 20 July 2018

Available online 25 August 2018

Kata Kunci:

Nilai Moral, Dongeng si

Kancil

Keywords:

moral value, fairy tale $f$ the mouse deer.

\begin{abstract}
A B S T R A K
Penelitian ini bertujuan untuk mengetahui apa saja nilai moral yang terkandung dalam buku dongeng si Kancil.Tujuan yang hendak dicapai dalam penelitian ini adalah untuk menganalisis dan mendeskripsikan nilai moral yang terkandung dalam buku Dongeng Si Kancil karya Tira Ikranegara.Jenis penelitian ini adalah penelitian kualitatif, karena dalam menyimpulkan materi hasil analisis menggunakan kata-kata bukan dengan menggunakan angka, sedangkan tehnik pengumpulan datanya melalui analisis data. Setting penelitian ini yaitu di SDN 1 Kandangrejo. Metode pengumpulan data yang digunakan yaitu dengan melakukan wawancara kepada guru dan orang tua/wali siswa, mengedarkan angket kepada siswa yang didalamnya terdapat beberapa pertanyaan untuk siswa, dan dokumentasi yang diambil dari buku yang dianalis.Berdasarkan hasil penelitian menunjukkan terdapat nilai-nilai moral yang terkandung dalam buku Dongeng Si Kancil karya Tira Ikranegara ini, diantaranya seperti seperti sikap hormat, tanggung jawab, kejujuran, keadilan, toleransi, bijaksana, disiplin, suka menolong, berbelas kasih, kerja sama, berani dan demokratis. Nilai moral tersebut terwujud melalui cara mereka bercakap- cakap, serta melalui tindakan-tindakan yang dilakukannya.
\end{abstract}

\section{A B S T R A C T}

This study aims to find out what moral values are contained in the mouse deer book. The aim to be achieved in this research is to analyze and describe the moral values contained in the mouse deer book by Tira Ikranegara. This type of research is qualitative research, because in concluding the material the results of the analysis use word instead of using numbers, while the data collection techniques are through data analys. The setting of this study is in SDN 1 Kandangrejo. Data collection methods used are by conducting interviews with teachers and parents or guardians of students, circulating questionnaires to students in which there are several questions to students, and documentation taken from the analyzed book. Based on the results of the study shows there are moral values cntained in the tale book of the mouse deer by Tira Ikranegara, such as respect, responsibility, honesty, justice, tolerance, wisdom, discipline, helpfulness, compassion, cooperation, brave, and democratic. Moral values are realized through the way they talk, and through the actions they take.

\footnotetext{
${ }^{*}$ Corresponding author.

E-mail addresses: imamsetyowibowo@gmail.com (Imam setyo wibowo)
} 


\section{Pendahuluan}

Nilai moral adalah segala sesuatu yang kita alami sebagai ajakan dalam mengatur tingkah laku seseorang di masyarakat untuk melakukan perbuatan- perbuatan yang baik dan benar. Dilihat dari fungsi dan tujuannya dengan menanamkan nilai-nilai moral kepada anak, ini sesuai dengan fungsi dan tujuan dari pendidikan nasional yang tercantum dalam Undang-Undang SISDIKNAS. Adapun fungsi dan tujuan pendidikan nasional menurut UU RI No. 20 Tahun 2003 Bab II Pasal 3 sebagai berikut.

Pendidikan nasional berfungsi mengembangkan kemampuan dan membentuk watak serta peradaban bangsa yang berartabat dalam rangka mencerdaskan kehidupan angsa, bertujuan untuk berkembangnya potensi peserta didik agar menjadi manusia yang beriman dan bertakwa kepada Tuhan Yang Maha Esa, berakhlak mulia, sehat, berilmu, cakap, kreatif, mandiri, dan menjadi warga negara yang demokratis serta bertanggung jawab.

Berdasarkan hasil pengamatan peneliti ketika melaksanakan observasi di SD Negeri 1 Kandangrejo, terlihat bagaimana anak SD sekarang sudah mengalami penurunan moralnya. Mereka sering berkata tidak sopan, baik dengan mahasiswa yang sedang observasi maupun dengan guru-guru yang mengajar di sekolahan tersebut. Selain itu, mereka juga sering melakukan perkelahian serta berkata kotor terhadap teman sebayanya, hilangnya rasa kepedulian mereka dengan teman-temannya yang sedang mengalami masalah, dan lain sebagainya.

Menurut Notonegoro dalam Hermansyah, dkk (2000) mengatakan bahwa nilai moral yaitu nilai yang berkaitan dengan baik buruknya sikap dan perilaku manusia dalam berhubungan dengan orang lain. Beliau memasukkan nilai moral ke dalam kelompok nilai kerohanian. Sama halnya dengan pendapat Sheler dalam Depdiknas (2000) bahwa secara umum moral merupakan bagian dari nilai dan merupakan bagian dari nilai rohani. Setelah kita mengetahui pengertian nilai moral, tentu saja kita harus juga mengetahui apa tujuan dari pengembangan nilai moral. Adapun tujuan pendidikan dan pengembangan nilai moral ini menurut Adler dalam Otib (2005) adalah dalam rangka pembentukan kepribadian yang harus dimiliki oleh manusia seperti : "1) Dapat beradaptasi pada berbagai situasi dalam relasinya dengan orang lain dan dalam hubungannya dengan berbagai kultur; 2) Selalu dapat memahami sesuatu yang berbeda dan menyadari dirinya memiliki dasar pada identitas kulturnya; 3) Mampu menjaga batas yang tidak kaku pada dirinya, bertanggung jawab terhadap bentuk batasan yang di pilihnya sesaat dan terbuka pada perubahan". Beberapa perbedaan pandangan antara tokoh perkembangan moral yang satu dengan yang lainnya disebabkan karena perbedaan dasar filosofi dalam menyoroti perkembangan moral antara perkembangan moral menurut Dewey dalam Otib (2005) tahapan perkembangan moral seseorang itu akan melewati 3 fase sebagai berikut: "1) Fase pre moral atau pre conventional : pada kuel ini sikap dan perilaku manusia banyak dilandasi oleh impuls biologis dan sosial; 2) Tingkat konvensional : perkembangan moral pada manusia pada tahapan ini banyak didasari oleh sikap kritis kelompoknya; 3) Autonomous : pada tahapan ini perkembangan moral manusia banyak didasari pada pola pikirannya sendiri".

Selanjutnya Piaget mengemukakan bahwa seorang manusia dalam kehidupan akan melalui rentangan perkembangan moral yaitu : a). Tahapan heteronomous (anak usia 2 sampai dengan 6 tahun ). Pada usia ini anak masih sangat labil, mudah terbawa arus, mudah terpengaruh, dan dalam rangka pendidikan moral, mereka sangat membutuhkan bimbingan proses latihan serta pembiasaan yang terus menerus. Hal ini sesuai pendapat dari pusat pengembangan dan pendidikan anak usia dini (early childhood education \& development center, 2003 ) dalam Otib (2005) yang menyatakan anak membutuhkan latihan dan rutinitas; b). Tahapan autonomous, pada tahapan ini seorang anak manusia telah memiliki kemampuan sendiri dalam menentukan segala keputusan sikap dan perilaku moralitasnya, yang terbentuk dari proses pembelajaran dalam kehidupannya yang memungkinkan dirinya banyak menggunakan pertimbangan akal sehat, pengetahuan dan pengalaman hidupnya. Selanjutnya Kohlberg dalam Otib (2005) dalam teori perkembangan moral dan pandangan aliran perilaku ( behaviorist) tentang pembentukan perilaku moral pada anak. Ia mengemukakan "Pada awalnya anak berperilaku baik agar ia mendapatkan pujian terhindar dari hukuman, dan agar ia di terima oleh lingkungan sekitar dan terhindar dari kecaman orang lain". Menurut Musfiroh (2005) mengatakan bahwa perkembangan moral anak berlangsung secara berangsur-angsur tahap demi tahap. Terdapat tiga tahap dalam pertumbuhan ini: tahap amoral (anak tidak mempunyai rasa benar atau salah), tahap konvensional (anak menerima nilainilai atau norma dari orang tua dan masyarakat), tahap otonomi (anak membuat pilihan sendiri secara bebas). Gunarti, dkk (2005) mengemukakan bahwa bercerita adalah suatu kegiatan yang dilakukan seseorang untuk menyampaikan suatu pesan, informasi atau sebuah dongeng belaka, yang bisa dilakukan secara lisan atau tulisan. Cara penuturan cerita tersebut dapat dilakukan dengan menggunakan alat peraga atau tanpa alat peraga. Azis dalam Otib ( 2005 ) mengatakan bahwa " cerita yang baik adalah cerita 
yang mampu mendidik akal budi, imajinasi, dan etika seorang anak, serta bisa mengembangkan potensi pengetahuan yang ia miliki “.

Isi cerita harus dikaitkan dengan dunia kehidupan anak TK, maka mereka dapat memahami isi cerita itu, mereka akan mendengarkannya dengan penuh perhatian dan dengan mudah dapat menangkap isi cerita. Kegiatan bercerita harus di usahakan menjadi pengalaman bagi anak TK yang bersifat unik dan menarik, yang menggetarkan perasaan anak, dan memotivasi anak untuk mengikuti cerita itu sampai tuntas. Sebagai seorang guru harus memperhatikan dalam pemilihan cerita yang baik, yang cocok dengan kehidupan anak sehingga dapat mengundang perhatian anak secara utuh. Beberapa hal yang perlu diperhatikan untuk pemilihan cerita yang baik, yaitu: Cerita itu harus menarik dan memikat perhatian guru itu sendiri, kalau cerita itu menarik dan memikat perhatian, maka guru akan bersungguh-sungguh dalam menceritakan kepada anak secara mengasyikkan. Cerita itu harus sesuai dengan kepribadian anak, gaya, dan bakat anak, supaya memiliki daya tarik terhadap perhatian anak dan keterlibatan aktif dalam kegiatan bercerita. Cerita harus sesuai dengan tingkat usia dan kemampuan mencerna isi cerita anak usiaTK.

Menanamkan nilai-nilai moral dapat dilakukan melalui berbagai cara. Salah satu cara yang akan dibahas dalam penelitian ini adalah penanaman nilai moral melalui dongeng. Alasannya, karena di dalam sebuah dongeng pasti tersirat nilai-nilai moral yang nantinya dapat ditiru oleh anak. Selain itu, terkadang anak-anak juga merasa suka saat mendengarkan maupun membaca dongeng, apalagi dongeng yang berjenis fabel.

Menurut Priyono (dalam Ardini, 2012: 46) dongeng adalah cerita khayalan atau cerita yang mengada-ada serta tidak masuk akal dan dapat ditarik manfaatnya. Einon mengemukakan (dalam Ardini, 2012: 47) dongeng adalah cerita yang berisi kisah-kisah menakutkan, seperti ibu tiri yang jahat, anak-anak yang dipanggang dalam oven, dan serigala yang buas. Cerita-cerita tersebut disukai anak-anak karena memberikan kesempatan kepada anak untuk berimajinasi dengan menggambarkan peristiwaperistiwa tersebut ke dalam khayalan. Meskipun dongeng hanyalah berupa khayalan atau mengada- ada serta tidak masuk akal, namun memiliki informasi yang bermanfaat dari setiap ceritanya. Dalam cerita dongeng, akan memberikan gambaran anak mengenai tingkah laku moral di luar pengalamannya dan memberi ruang berkhayal bagi anak-anak secara terarah.

Pemaparan di atas menunjukkan, betapa pentingnya keberadaan dongeng di kalangan anak-anak dan orang tua dikarenakan dalam dongeng pasti tersirat pesan moral yang dapat diberikan kepada anakanak. Dengan penanaman moral yang dilakukan sejak kecil, anak akan dituntun untuk berpikir dan membangun etika dan karakter yang baik, sehingga ketika dewasa kelak, anak-anak memiliki kepribadian dan karakter yang kokoh.

Peneliti memilih dongeng si Kancil karena sudah jarangnya penggunaan dongeng tersebut dalam beberapa buku pelajaran di Sekolah Dasar, padahal masih banyak anak yang menyukai dongeng ini. Ketika seorang anak menyukai cerita atau dongeng, biasanya anak akan dengan mudah memahami dan menyimpulkan isi cerita atau dongeng tersebut. Dongeng si Kancil ini mungkin terlihat kurang baik bagi anak-anak karena dalam ceritanya mengisahkan kancil yang nakal, suka menipu binatang lain dan mencuri timun. Namun dibalik itu semua, masih banyak kisah dongeng si Kancil lainnya yang mungkin beberapa orang belum mengetahuinya. Dimana dongeng-dongeng tersebut memiliki beberapa pesan nilai moral yang baik, sehingga dapat ditiru dan diteladani oleh anak-anak yang membaca maupun mendengarkan ceritanya.

Dongeng dan legenda memang banyak yang tidak masuk akal, namun pesan moral yang terkandung didalamnya patut untuk dijadikan teladan bagi anak-anak yang membacanya. Oleh karena itu, peneliti menganalisis nilai moral dalam buku Dongeng Si Kancil karya Tira Ikranegara dan buku Kumpulan Cerita Rakyat Nusantara karya Yudhistira Ikranegara, karena dalam buku ini mengisahkan beberapa dongeng si Kancil. Penelitian ini dapat dijadikan bahan pertimbangan bagi guru dan orang tua dalam mengembangkan bahan ajar dalam menanamkan nilai-nilai moral pada anak.

\section{Metode}

Jenis penelitian ini adalah penelitian deskriptif kualitatif, karena dalam menyimpulkan materi hasil analisis menggunakan kata-kata bukan dengan menggunakan angka, sedangkan tehnik pengumpulan datanya melalui analisis data. Dalam penelitian deskriptif kualitatif, data yang dikumpulkan adalah data yang berupa kata-kata, gambar, dan bukan angka-angka. Data tersebut dapat dimungkinkan berasal dari naskah wawancara, catatan lapangan, foto, videotape, dokumen pribadi, catatan atau memo, dan dokumen resmi lainnya. Dengan demikian, laporan penelitian akan berisi kutipan-kutipan data untuk memberi gambaran penyajian laporan tersebut. (Moleong, 2007:11). 
Penelitian deskriptif yaitu penelitian yang tidak dilakukan di lapangan (noneksperimen). Setting penelitian ini yaitu dengan mengumpulkan sumber dan mengkaji serta mengumpulkann kajian pustaka. Penelitian ini meneliti nilai moral yang terkandung dalam buku Dongeng Si Kancil Karya Tira Ikranegara. Lokasi penelitian ini dilakukan di SD Negeri 1 Kandangrejo. Dengan memilih siswa, orang tua/wali siswa serta guru yang ada di SD Negeri 1 Kandangrejo sebagai subjek penelitiannya. Populasi dalam penelitian ini adalah seluruh cerita dongeng pada buku Dongeng Si Kancil Karya Tira Ikranegara yang terdiri dari 9 cerita.

Tehnik pengumpulan data merupakan langkah-langkah yang paling penting dalam penelitian, karena tujuan utama dari penelitian adalah mendapatkan data. Tanpa mengetahui tehnik pengumpulan data apa yang akan digunakan, maka peneliti tidak akan mendapatkan data yang sesuai dengan standar data yang telah ditetapkan (Sugiyono, 2014: 224). Pengumpulan data dilakukan dalam berbagai setting dan berbagai sumber. Dalam pengumpulan data yang dibutuhkan, peneliti menggunakan tehnik penumpulan data wawancara, angket, dan dokumentasi.

\section{Hasil dan pembahasan}

\section{Dekripsi Data}

Penelitian ini adalah penelitian deskriptif kualitatif. Data yang diteliti adalah data yang terdapat pada buku Dongeng Si Kancil Karya Tira Ikranegara yang berjumlah 32 halaman dan buku Kumpulan Cerita Rakya Nusantara karya Yudhistira Ikranegara yang berjumlah 32 halaman. Dalam buku tersebut memuat 6 kisah dan ditambah 3 kisah dari buku Kumpulan Cerita Rakyat Nusantara . Data tersebut selanjutnya dianalisis berdasarkan kartu data. Deskripsi akan dilakukan pada masing- masing dongeng yang dianalisis dengan memberikan bukti kalimat yang mengandung nilai moral yang terkandung dalam dongeng

\section{Analisis Kartu Data}

Analisis kartu data dari buku Dongeng Si Kancil karya Tira Ikranegara dalam penelitian ini didasarkan pada 12 nilai-nilai moral yang perlu diajarkan di sekolahan.

Tabel 1. Judul Cerita Dongeng

\begin{tabular}{lll}
\hline & \multicolumn{1}{c}{ Jo } & \multicolumn{1}{c}{ Nilai Moral } \\
& & 4 \\
\hline 1 & Kancil Menipu Kera & 5 \\
\hline 2 & Gajah Yang Pintar & 3 \\
\hline 3 & Kancil Dengan Babi Yang Sombong & 5 \\
\hline 4 & Hakim Yang Cerdik & 1 \\
\hline 5 & Si Kancil Dan Beruang & 3 \\
\hline 7 & Kancil Dan Burung Puyuh & 3 \\
\hline 8 & Kancil Mencuri Timun & 3 \\
\hline
\end{tabular}

Berdasarkan tabel 4.1 di atas terdapat 9 judul dongeng yang dianalisis nilai moral. Berikut adalah sinopsis dari 9 judul di atas :

Kancil Menipu Kera

Unsur instrinsik dari kancill menipu kera antara lain:
a. Tema
: Kancil mencari cara untuk mendapatkan pisang
b. Tokoh
: Kancil dan Kera
c. Watak
: Kancil cerdik dan Kera keras kepala dan rakus.
d. Alur : Maju
e. Latar : Tempat kebun pisang, waktu pagi hari, suasana menegangkan, menyedihkan. 
Nilai karakter yang terkandung yaitu nilai sikap hormat, kejujuran, bijaksana, berani.

Gajah Yang Pintar

Unsur instrinsik dari gajah yang pintar antara lain:

a. Tema : Gajah menyadarkan kancil agar berbuat baik

b. Tokoh : Gajah, Harimau, dan Kancil

c. Watak : Gajah pintar dan baik hati, Harimau baik hati, Kancil suka berbohong

d. Alur : Maju

e. Latar : Tempat hutan dan kolam, waktu siang hari, suasana menegangkan, menyedihkan dan menyenangkan.

Nilai karakter yang terkandung yaitu nilai sikap hormat, kejujuran, toleransi, bijaksana, suka menolong.

Kancil Dengan Babi Yang Sombong

Unsur instrinsik dari kancil dengan babi yang sombong antara lain:
a. Tema : Kancil yang menyadaran babi agar tidak bersikap sombog
a. Tokoh : Kancil dan babi
b. Watak : Kancil cerdika, baik hati dan Babi sombong
c. Alur : Maju
d. Latar : Tempat hutan, waktu siang dan pagi hari, suasana menegangkan
Nilai karakter yang terkandung yaitu nilai kejujuran, disiplin, dan berani

Hakim Yang Cerdik

.Unsur instrinsik dari hakim yang cerdik antara lain:
a. Tema
: Kancil memberi pelajaran terhadap buaya yang tidak tau berterimakasih.
b. Tokoh
: Ibu Sapi, Anak Sapi, Buaya, Kancil
c. Watak : Kancil cerdik, Ibu Sap baik hati, Anak Sapi baik hati, dan Buaya bodoh, jahat
d. Alur : Maju
e. Latar : Tempat pinggir sungai dan hutan, waktu siang hari, suasana menegangkan dan senang.
Nilai karakter yang terkandung yaitu sikap homat, kejujuran, toleransi, bijaksana, berbelas kasih.

Si Kancil Dan Beruang

Unsur instrinsik dari si kancil dan beruang antara lain:
a. Tema
b. Tokoh
: Kancil yang pintar bermin musik.
c. Watak
: Kancil, dan Beruang
d. Alur
: Kancil cerdik, dan Beruang polos
e. Latar : Tempat hutan bambu, waktu sian
Nilai karakter yang terkandung yaitu bijaksana.
: Maju

Kancil Dan Burung Puyuh.

Unsur instrinsik dari kancil dan burung puyuh antara lain:
a. Tema : Kancil dan teman-teman bekerjasama untuk membalas kejahatan pak Congkak.
b. Tokoh : Burung puyuh, kancil, kayu kopi, napal, pak Congkak
c. Watak : Kancil cerdik, burung puyuh baik hati, napal baik hati, kayu kopi baik hati, dan pak Congkak jahat.
d. Alur : Maju
e. Latar : Tempat pedesaan rumah pak Congkak, waktu siang, dan malam hari, suasana menegangkan.
Nilai karakter yang terkandung yaitu kejujuran, kerja sama, demokrasi.

\section{Kancil Mencuri Timun}

Unsur instrinsik dari kancil mencuri timun, antara lain:
a. Tema
: Kancil yang suka mencuri dan merusak tanaman.
b. Tokoh
: Kancil, pak Tani, anjing.
c. Watak
: Kancil suka menipu, pak Tani baik hati, anjing bodoh.
d. Alur : Maju.
e. Latar : Tempat pedesaan rumah pak Tani dan kebun mentimun, waktu siang, dan malam hari, suasana menegangkan.
Nilai karakter yang terkandung yaitu tanggung jawab, toleransi, berbelas kasih. 
Kancil Menipu Para Buaya.

Unsur instrinsik dari kancil menipu para buaya, antara lain:
a. Tema
: Kancil yang cerdik untuk mendapatkan makanan.
b. Tokoh
: Kancil dan Buaya.
c. Watak
: Kancil cerdik, Buaya bodoh.
d. Alur : Maju.
e. Latar : Tempat sungai, waktu siang hari, suasana menegangkan
Nilai karakter yang terkandung yaitu keadilan, toleransi, dan berani.

\section{Kancil Menipu Harimau}

Unsur instrinsik dari kancil menipu harimau, antara lain:
a. Tema
: Kancil yang cerdik untuk lolos dari harimau.
b. Tokoh
: Kancil, harimau dan ular.
c. Watak
d. Alur : Maju.
e. Latar : Tempat hutan, waktu siang hari, suasana menegangkan
: Kancil cerdik, harimau bodoh, ular bodoh.
Nilai karakter yang terkandung yaitu tanggung jawab, toleransi, dan berani.

\section{Analisis Hasil Wawancara}

Dalam penelitian ini, peneliti melakukan wawancara dengan beberapa guru di SDN 1 Kandangrejo seperti Bapak Suwardi, S.Pd. Beliau merupakan Kepala Sekolah di SD tersebut, beliau juga merupakan salah satu guru senior yang paling sering memberikan bimbingan dan penyuluhan kepada siswa. Setelah itu saya mewawancarai guru kelas 3 Ibu Dwida Susanti S.Pd. Menurut keterangan beberapa narasumber yang peneliti wawancarai tersebut, untuk kondisi moral siswa Sekolah Dasar terutama untuk SDN 2 Kandangrejo hampir sama jawabannya, kondisi anak-anak di sekolahan tersebut ada yang nakal ada pula yang baik. Mereka nakal disebabkan karena memang mereka itu usil. Terutama untuk anak-anak kelas 3 yang memang dalam masa-masanya untuk bermain dan juga peralihan dari kelas rendah menuju kelas tinggi sehingga cukup sulit untuk diarahkan dengan baik. Diperlukan waktu untuk dapat mengarahkan mereka. Penyebab dari kenakalan-kenakalan tersebut kebanyakan dikarenakan kurangnya pengawasan, perhatian dan kasih sayang dari orang tua di rumah. Kebanyakan mereka yang nakal itu karena orang tuanya sibuk dengan pekerjaannya, ada pula yang pulangnya hingga larut malam. Jadi ketika berada di rumah anak itu menjadi kurang pengawasannya, akhirnya mereka melampiaskan keusilan mereka dengan temannya

\section{Hasil Angket}

Angket dalam pengumpulan data penelitian ini yaitu dengan mengedarkan formulir yang berisikan beberapa pertanyaan kepada siswa kelas3 di SDN 1 Kandangrejo. Angket ini digunakan untuk mencari beberapa informasi dari siswa serta mengetahui minat siswa terhadap dongeng Si Kancil. Total keseluruhan dari responden ini adalah 16 siswa yang merupakan siswa kelas 3. Berikut Tabel hasil rekapitulasiangket.

Tabel 2. Rekapitulasi Angket

\begin{tabular}{cccccccccccc}
\hline \multirow{2}{*}{ No Nama } & \multirow{8}{*}{ No Pertanyaan } \\
\cline { 2 - 11 } & Afif Koirul Umam & $\mathbf{1}$ & $\mathbf{2}$ & $\mathbf{3}$ & $\mathbf{4}$ & $\mathbf{5}$ & $\mathbf{6}$ & $\mathbf{7}$ & $\mathbf{8}$ & $\mathbf{9}$ & $\mathbf{1 0}$ \\
\hline 1 & Gura & 0 & 1 & 0 & 1 & 1 & 1 & 1 & 0 & 0 \\
\hline 2 & Davian & 1 & 0 & 1 & 0 & 1 & 1 & 1 & 1 & 0 & 0 \\
\hline 3 & Desi & 1 & 0 & 1 & 0 & 1 & 1 & 1 & 0 & 1 & 0 \\
\hline 4 & Ilham & 1 & 0 & 1 & 0 & 1 & 1 & 1 & 1 & 0 & 0 \\
\hline 5 & Indi & 1 & 0 & 1 & 0 & 1 & 1 & 1 & 1 & 0 & 0 \\
\hline 6 & Ajik & 1 & 0 & 1 & 0 & 1 & 1 & 1 & 1 & 0 & 0 \\
\hline 7 & Erik & 1 & 0 & 1 & 0 & 1 & 1 & 1 & 1 & 0 & 0 \\
\hline 8 & Sobri & 1 & 0 & 1 & 0 & 1 & 1 & 1 & 1 & 0 & 0 \\
\hline 9 & Nadzia & 1 & 0 & 1 & 0 & 1 & 1 & 1 & 1 & 0 & 1 \\
\hline 10 & Wida & 1 & 1 & 1 & 0 & 1 & 1 & 1 & 1 & 0 & 0 \\
\hline 11 & & & & & & & & & & & \\
\hline
\end{tabular}




\begin{tabular}{lcrrrrrrrrrr}
\hline 12 & Aditya & 1 & 0 & 1 & 0 & 1 & 1 & 1 & 1 & 0 & 0 \\
\hline 13 & Candra & 1 & 0 & 1 & 0 & 1 & 1 & 1 & 1 & 0 & 0 \\
\hline 14 & Dias & 1 & 0 & 1 & 0 & 1 & 1 & 1 & 1 & 0 & 0 \\
\hline 15 & Syifa & 1 & 0 & 1 & 0 & 1 & 1 & 1 & 1 & 0 & 0 \\
\hline 16 & Fadli & 1 & 0 & 1 & 0 & 1 & 1 & 0 & 1 & 0 & 1 \\
\hline & & $\mathbf{1 6}$ & $\mathbf{0}$ & $\mathbf{1 6}$ & $\mathbf{0}$ & $\mathbf{1 6}$ & $\mathbf{1 6}$ & $\mathbf{1 5}$ & $\mathbf{1 5}$ & $\mathbf{1}$ & $\mathbf{1}$ \\
\hline
\end{tabular}

Dari hasil angket di atas terlihat sebanyak 16 siswa menyukai buku dongeng, namun tidak ada siswa yang mengaku memiliki beberapa buku dongeng. Semua siswa mengaku mengetahui dongeng si Kancil, dan tidak ada siswa yang mengaku sering membaca dongeng si Kancil ini. Siswa lebih menyukai menonton tayangan si Kancil ini di televisi yaitu pada acara "Pada Zaman Dahulu" yang tayang disalah satu stasiun televisi nasional dibandingkan membaca dongengnya secara langsung.

Terdapat 16 siswa yang mengaku menyukai dongeng si Kancil karena dongengnya lucu, dan ada 15 siswa yang menyukai karakter si Kancil karena memiliki sifat pemberani dan suka menolong. Bapak dan Ibu Guru di sekolah sepertinya jarang atau bahkan tidak pernah mendongengkan dongeng si Kancil karena hanya ada 1 siswa dari keseluruhan 16 siswa yang mengaku Bapak dan Ibu Gurunya pernah mendongengkan dongeng si Kancil. Hal tersebut dimungkinkan terjadi karena sudah jarangnya buku pelajaran atau materi pelajaran yang menceritakan dongeng si Kancil ini. Berbeda dengan hasil wawancara sebelumnya, dimana hampir semua narasumber yang peneliti wawancarai mengaku tidak pernah mendongengkan dongeng si Kancil ini, namun bedasarkan hasil angket terdapat 1 siswa yang mengaku orang tua di rumahnya pernah mendongengkan dongeng si Kancil. Perbedaan hasil ini dimungkinkan terjadi karena kesibukan setiap orang tua tentunya berbeda antara yang satu dengan lainnya.

Dari penelitian yang telah peneliti lakukan, dalam buku Kumpulan Dongeng Si Kancil karya Tira Ikranegara ternyata banyak ditemukan berbagai macam nilai moral yang dapat digunakan untuk menanamkan nilai moral pada anak. Penyampaian moral pada cerita dapat dilihat melalui cara mereka bercakap-cakap, serta melalui tindakan-tindakan yang dilakukannya. Melalui dongeng-dongeng yang ada di dalam buku ini anak akan diajarkan nilai-nilai moral seperti sikap hormat, tanggung jawab, kejujuran, keadilan, toleransi, bijaksana, disiplin, suka menolong, berbelas kasih, kerja sama, berani dan demokratis, yang tentunya akan berguna untuk perkembangan tumbuh moral anak.

Dari hasil wawancara (terlampir), meskipun si Kancil ini terkenal suka mencuri dan menipu, namun banyak orang yang manyetujui jika dongeng- dongeng si Kancil ini mampu dijadikan sebagai sarana untuk menanamkan nilai moral pada anak. Apalagi berdasarkan dari hasil angket (terlampir), diketahui bahwa banyak siswa yang mengenal dan menyukai dongeng si Kancil ini. Tentunya, ketika seorang anak menyukai cerita atau dongeng, biasanya anak akan dengan mudah memahami dan menyimpulkan isi cerita atau dongeng tersebut. Tinggal bagaimana cara guru maupun orang tua menyampaikan isi dongeng tersebut, dengan mengajak anak untuk mengikuti, meniru, meneladani segi positif dari dongeng tersebut dan membuang segi negatifnya.

\section{Simpulan dan saran}

Berdasarkan hasil penelitian dalam pembahasan yang telah diuraikan di atas dapat disimpulkan bahwa terdapat nilai-nilai moral dalam buku Kumpulan Dongeng Si Kancil karya Tira Ikranegara Nilai moral tersebut terwujud melalui cara mereka bercakap-cakap, serta melalui tindakan-tindakan yang dilakukannya. Dengan nilai-nilai moral tersebut diharapkan mampu mendidik, menasihati serta memberi contoh untuk berbuat baik.

Dalam penelitian ini, nilai-nilai moral yang terkandung diantaranya adalah sikap hormat, tanggung jawab, kejujuran, keadilan, toleransi, bijaksana, disiplin, suka menolong, berbelas kasih, kerja sama, berani dan demokratis. Diharapkan setelah membaca buku ini, pembaca dapat mencontoh nilai-nilai moral yang baik untuk digunakan dalam kehidupan sehari-hari. Jika seekor hewan seperti kancil saja dapat menggunakan akal dan pikirannya ketika dia mendapatkan masalah atau pun merasa terdesak, mengapa kita sebagai manusia yang diberikan kelebihan akal dan pikiran tidak bisa. Selain itu, diharapkan pembaca juga dapat menggunakan dongeng- dongeng yang ada di dalam buku ini sebagai sarana untuk menanamkan nilai moral pada anak. 


\section{Daftar Rujukan}

Ardini, Pupung Puspa. 2012. “Pengaruh Dongeng dan Komunikasi Terhadap Perkembangan Moral Anak Usia 7-8 Tahun". Jurnal Pendidikan Anak, Volume 1, Edisi 1, Juni 2012. http://journal.uny.ac.id/index.php/jpa/article/view/2905/2419. Diakses 27 Oktober 2015

Arikunto, Suharsimi, dkk. 2006. Penelitian Tindakan Kelas. Jakarta : PT Bumi Aksara

Aqib, Zainal. (2009). Belajar dan Pembelajaran di Taman Kanak-Kanak. Bandung: TYRAMA WIDYA

Darmansyah. 2009. Penelitian Tindakan Kelas. Padang: Suja Bina Pres.

---.-. 2000. Metode Pengembangan Agama, Moral dan Disiplin yang Efektif. Jakarta: Depdiknas.

Dervarics, Charles (2005). Rural Children Lag in Early Chilhood Education Skill.Washington DC: Population Reference Bureau .

Erna Purba, Abas Yusuf, Indri Astuti.2013."Peningkatan Nilai-Nilai Agama dan Moral Melalui Metode Bercerita Pada Anak Usia 4-5 Tahun". Pg-Paud Fkip Universitas Tanjungpura Pontianak

Gunarti, dkk. 2005. Metode Pengembangan Prilaku dan Kemampuan Dasar Anak Usia Dini. Jakarta : Universitas Terbuka.

Haryadi. 2009. Statistik Pendidikan. Jakarta: Prestasi Pustaka Raya.

Heni, Anastasia. 2010. Perkembangan Anak Usia Dini. Jakarta : CWS Indonesia

Hermansyah, dkk. 2000. Metode Pengembangan Agama, Moral, Disiplin, dan Afeksi. Bandung: Depdiknas.

Irma Sari. 2012."Peningkatan Nilai-Nilai Moral Anak Melalui Bercerita, Permainan Papan Magnet di Raudhatul Athfal Baburrahman Padang Pariaman". Pesona PAUD. Vol. I No.1

Koesoema A. Doni. (2007). Pendidikan Karakter. Jakarta: Grasindo.

Musfiroh, Tadkiroatun. 2005. Bermain sambil Belajar dan Mengasah Kecerdasan. Jakarta: Departemen Pendidikan Nasional.

Moleong, Lexy J. 2007. Metode Penelitian Kualitatif Edisi Revisi. Bandung: PT Remaja Rosdakarya Offset.

Otib, Satibi Hidayat. 2005. Metode Pengembangan Moral dan Nilai-nilai Agama. Jakarta : Universitas Terbuka

Rini, Hildayani. 2004. Psikologi Perkembangan Anak. Jakarta : Universitas Terbuka.

Suhendiana, dkk. 2007. Mari Bermain Magnet. Bandung: PT. Setia Purna Inves.

Sugiyono. 2014. Metode Penelitian Kuantitatif, Kualitatif, dan R\&D. Bandung:Alfabeta.

Undang-Undang RI No. 20. 2003. Sistem Pendidikan Nasional. Jakarta : Dikti. 